\title{
Optimizing breast cancer surgery during the COVID-19 pandemic
}

\author{
M. Ahmed ${ }^{1}$ (1) \\ Received: 8 June 2020 / Accepted: 11 September 2020 / Published online: 18 September 2020 \\ (c) The Japanese Breast Cancer Society 2020
}

\begin{abstract}
The COVID-19 pandemic poses current and future challenges in the maintenance of surgical operating capacity. In the United Kingdom surgery has continued—in a reduced capacity—-through the establishment of regional 'cancer hubs' using independent sector facilities to treat public healthcare patients. It is essential that these scarce operating facilities available are optimally utilized and that logistical challenges that result from remote operating away from the surgeon's primary hospital site are considered. These issues are best addressed through the application of currently available medical technology and enhanced training in advanced oncoplastic techniques, which extend the limits of breast conservation.
\end{abstract}

The COVID-19 Pandemic has posed great challenges for the maintenance of breast cancer surgical services. One of the greatest problems posed has been ensuring continued provision of operating theatre capacity-for existing patients and those newly diagnosed. Extensive commentary and guidelines have been provided by national bodies regarding the prioritization of surgery according to different breast cancer categories $[1,2]$. These are useful guidelines in the absence of full operative theatre capacity. However, during the ongoing pandemic, little has been mentioned regarding the adverse logistical issues, which the breast surgical oncologist encounters that can potentially compromise their patient's management. From a United Kingdom perspective, the establishment of 'breast cancer regional hubs' by the Department of Health was aimed at centralizing surgical management in independent sector (private) hospital facilities, which would be free from the treatment of COVID-19 patients and reduce the likelihood of breast cancer patient exposure to the virus. Such a 'cancer hub', whilst maintaining theatre availability, must understandably prioritize and hence the numerous guidelines created with a similar ethos are applicable. However, the logistical issues of operating in a remote hub away from a surgeon's base hospital in turn poses potential challenges - particularly to breast cancer surgery. These challenges are based upon the ill-defined line

M. Ahmed

muneer.ahmed@ucl.ac.uk

1 Division of Surgery and Interventional Science, University College London, Royal Free Hospital, 9th Floor (East), Pond Street, London NW3 2QG, UK between surgical oncology, radiology and plastic surgery in the comprehensive management of breast cancer. It is imperative that these logistical issues are identified now in the first wave of the pandemic and solutions created and applied for current as well as future application.

Breast surgical oncology is highly dependent upon radiology. It is widely accepted that between $30-50$ per cent of breast cancers are radiologically identified, either through screening or incidentally using advanced imaging modalities [3]. Although screening is suspended, the already diagnosed will still be present and warrant management during the pandemic. A proportion of patients once diagnosed are subsequently identified to have multifocality or centricity on more comprehensive imaging. These patients require localization-guidance to be performed during surgery. In the context of a regional hub, issues can be raised regarding the site (base hospital or hub) of radiological performance of localizations - according to capacity - and the ability of the 'in transit' surgeon to be able to view preoperative images to plan their surgery in an alien hospital. These may seem very simple issues to address, but within the bureaucratic world of different institutional processing, it can be the most taxing. These issues could all be overcome by the simple application of currently available technology. There currently are $3 \mathrm{CE}$-marked radioisotope-independent seed localization technologies (Magseed-Endomag, Cambridge, UK; Localizer-Hologic, MA, USA; Savi Scout-Cianna Medical, Aliso Viejo, USA) and all could potentially be placed into any suspicious lesion at the time of core-biopsy and should the lesion be confirmed as requiring excision, the patient would not require a further localization procedure prior to 
definitive surgery. In the context of a pandemic-economic benefit aside - this means reduced visits to a hospital and reduced potential exposure to the virus either in the hospital or in transit to and from it. Another option-in view that 95 per cent of breast lesions are visible on ultrasound-is for surgeons to be trained in intraoperative ultrasound-guided excision $[4,5]$. This would also eliminate the need for separate localization procedures once a cancer diagnosis has been confirmed. In the event of ultrasound occult lesions, ultrasound visible markers should be placed at biopsy in order to allow excision. I accept that the latter is more contentious in terms of radiology and surgery 'turf wars' regarding clinical practice and training, but this really should be irrelevant when it comes to optimizing patient management and reducing risk of virus exposure. The pandemic highlights how such practices can be invaluable in reducing visitation to healthcare facilities and potentially save lives.

Another stalwart of breast surgery is axillary staging using sentinel node biopsy. This again can create a logistical nightmare in terms of the location of a nuclear medicine department and mandates another visitation to either an extra department or separate hospital. This extra travel is accepted to be unsatisfactory in any day to day scenario but could cost lives in a pandemic. In addition, the delay to the start of a list for nuclear medicine attendance is a complete waste of scarce operative capacity, which could be allocated to another much needed case. These issues can all be addressed by the surgeon taking control of the injection procedure using radioisotope-free tracers. The use of indocyanine green providing visualization with a photodynamic camera and the magnetic technique using a magnetic tracer and magnetometer have both been widely used and evaluated in trials and systematic reviews [6,7]. They both provide safe, reliable performance of sentinel node biopsy, which is surgeon directed—avoiding unnecessary additional hospital or departmental visits, streamlining the patient pathway.

National guidelines have generally advised against the use of primary systemic therapy (PST) in all but inoperable cases $[1,2]$. This has meant a situation has been created whereby more locally advanced cancers are potentially going to warrant more radical treatment in terms of mastectomy and less of an opportunity for breast conservation than if PST was available. With a general moratorium on immediate breast reconstruction (IBR), this is a devastating situation for patients. However, this situation - of the absence of PST and IBR - presents an opportunity for the proliferation of therapeutic mammaplasty to extend the realms of breast conservation. Cases deemed requiring mastectomy on the basis of size or multifocality could in suitably trained hands be breast conservable. The application of minimal skin reduction patterns using vertical mammaplasty and a quadrant by quadrant approach can minimise complication rates and potential for excessive hospital attendances from wound healing issues [8-10]. These techniques are generally well disseminated but suffer from widespread disparity in their utilization-even amongst surgeons within the same breast unit. This is mainly based upon a lack of training and experience, meaning It is imperative that all breast surgeonswhatever level-have the opportunity to subspecialize and gain skills in this area. Indeed, it may be a consequence of the pandemic that it serves to reduce the reliance upon PST and return it back towards the adjuvant realm. Therapeutic mammaplasty should not be considered a 'fanciful' luxury, but rather a very standard practice to maintain high quality patient outcomes and extend the limits of breast conservation. It is a practice that should be embraced with the pandemic and not limited.

The COVID-19 pandemic has been and continues to be a tragedy of immeasurable, human and economic suffering. However, the long-term consequences of inadequate cancer care will plague us for a generation and beyond if we do not learn from our experiences. The COVID-19 pandemic has reinforced the benefits of already existing technologies and techniques - present for several years-but underutilized. These practices could all be employed rapidly within any breast cancer centre. It is imperative that we embrace these technologies and training in order to be better prepared for comprehensive breast cancer management of our patients in future 'waves' of this virus and for any other virus - which likely will—develop in future.

\section{Compliance with ethical standards}

Conflict of interest MA has received an unrestricted educational research grant from Endomag previously. MA has received a speaker honorarium from Hologic BVBA.

Ethical approval This article does not contain any studies with human participants or animals performed by the author.

\section{References}

1. Curigliano G, Cardoso MJ, Poortmans P, Gentilini O, Pravettoni G, Mazzocco K, Houssami N, Pagani O, Senkus E, Cardoso F, editorial board of The B. Recommendations for triage, prioritization and treatment of breast cancer patients during the COVID-19 pandemic. Breast. 2020;52:8-16.

2. Dietz JR, Moran MS, Isakoff SJ, Kurtzman SH, Willey SC, Burstein HJ, Bleicher RJ, Lyons JA, Sarantou T, Baron PL, Stevens RE, Boolbol SK, Anderson BO, Shulman LN, Gradishar WJ, Monticciolo DL, Plecha DM, Nelson H, Yao KA . Recommendations for prioritization, treatment, and triage of breast cancer patients during the COVID-19 pandemic. the COVID-19 pandemic breast cancer consortium. Breast Cancer Res Treat. 2020;181(3):487-97. 
3. Ahmed M, Anninga B, Goyal S, Young P, Pankhurst QA, Douek M, Mag STG. Magnetic sentinel node and occult lesion localization in breast cancer (MagSNOLL Trial). Br J Surg. 2015;102(6):646-52.

4. Ahmed M, Abdullah N, Cawthorn S, Usiskin SI, Douek M. Why should breast surgeons use ultrasound? Breast Cancer Res Treat. 2014;145(1):1-4.

5. Ahmed M, Douek M. Intra-operative ultrasound versus wireguided localization in the surgical management of non-palpable breast cancers: systematic review and meta-analysis. Breast Cancer Res Treat. 2013;140(3):435-46.

6. Ahmed M, Purushotham AD, Douek M. Novel techniques for sentinel lymph node biopsy in breast cancer: a systematic review. Lancet Oncol. 2014;15(8):e351-362.

7. Zada A, Peek MC, Ahmed M, Anninga B, Baker R, Kusakabe M, Sekino M, Klaase JM, Ten Haken B, Douek M. Meta-analysis of sentinel lymph node biopsy in breast cancer using the magnetic technique. Br J Surg. 2016;103(11):1409-19.
8. Clough KB, Gouveia PF, Benyahi D, Massey EJ, Russ E, Sarfati I, Nos C. Positive margins after oncoplastic surgery for breast cancer. Ann Surg Oncol. 2015;22(13):4247-53.

9. Clough KB, Lewis JS, Couturaud B, Fitoussi A, Nos C, Falcou MC. Oncoplastic techniques allow extensive resections for breast-conserving therapy of breast carcinomas. Ann Surg. 2003;237(1):26-34.

10. Clough KB, la van Parra RFD, Thygesen HH, Levy E, Russ E, Halabi NM, Sarfati I, Nos C. Long-term results after oncoplastic surgery for breast cancer: a 10-year follow-up. Ann Surg. 2018;268(1):165-71.

Publisher's Note Springer Nature remains neutral with regard to jurisdictional claims in published maps and institutional affiliations. 